\title{
Association of Inflammation with Metabolic Syndrome among Low-Income Rural Kazakh and Uyghur Adults in Far Western China
}

\author{
Yi-Zhong Yan, ${ }^{1}$ Ru-Lin Ma, ${ }^{1}$ Yu-Song Ding, ${ }^{1,2}$ Heng Guo, ${ }^{1}$ Jing-Yu Zhang, ${ }^{1}$ \\ La-Ti Mu, ${ }^{1}$ Mei Zhang, ${ }^{1}$ Jia-Ming Liu, ${ }^{1}$ Dong-Sheng Rui, ${ }^{1}$ Jia He, ${ }^{1}$ Feng Sun, ${ }^{3}$ \\ Kui Wang, ${ }^{1}$ and Shu-Xia Guo ${ }^{1,2}$ \\ ${ }^{1}$ Department of Preventive Medicine, University of Shihezi, Shihezi 832000, China \\ ${ }^{2}$ Department of Pathology and Key Laboratory of Xinjiang Endemic and Ethnic Diseases (Ministry of Education), \\ Shihezi University School of Medicine, Shihezi 832000, China \\ ${ }^{3}$ Department of Epidemiology and Bio-Statistics, School of Public Health, Peking University Health Science Center, \\ Beijing 100000, China
}

Correspondence should be addressed to Shu-Xia Guo; yyz19880215@sina.com

Received 28 April 2015; Revised 12 June 2015; Accepted 16 June 2015

Academic Editor: Ariadne Malamitsi-Puchner

Copyright (C) 2015 Yi-Zhong Yan et al. This is an open access article distributed under the Creative Commons Attribution License, which permits unrestricted use, distribution, and reproduction in any medium, provided the original work is properly cited.

\begin{abstract}
This study focused on low-income rural and nomadic minority people residing in China's far west and investigated their relationship between inflammatory markers (IL-6, hsCRP, FFA, and adiponectin) and MS and ethnic differences. And it found that improving behavioral lifestyle by education or using drugs to control inflammation may prevent MS. These observations may benefit lowincome populations.
\end{abstract}

\section{Introduction}

Metabolic syndrome (MS) comprises a cluster of clinical metabolic diseases that include hypertension, insulin resistance (IR), obesity, and dyslipidemia [1-3]. MS is a global public health problem that affects all nations and all races, and estimates suggest that approximately $1 / 4-1 / 3$ of the global population is affected by MS and that its prevalence will continue to increase [4].

China is a multiethnic country, with more than 10 ethnic groups in Xinjiang. In this region, Kazakh and Uyghur populations constitute large minority groups, with most individuals residing in low-income rural communities [5]. For example, more than $92 \%$ of Uyghurs in Jiashi County live on US $\$ 1.00$ per day or less, and this percentage is much higher than the national average reported in 2005 (15.9\%) [6, 7]. Due to a primitive economic system, limited public health resources, and a poor transportation system, few serious investigations have focused on the analyses of local public health issues, including the prevalence of hypertension, obesity, dyslipidemia, and related diseases such as diabetes and cardiovascular diseases (CVDs). Our previous studies demonstrated an MS prevalence of $21.2 \%$ in Uyghurs [8] and $26.6 \%$ in Kazakhs [9]; these values are significantly higher than the national average of $16.5 \%$ [10]. Differences in religion, culture, lifestyle, diet, and genetic background in these ethnic groups may be related to this high MS prevalence, and knowledge about these differences may be useful for establishing appropriate preventive public health policies for Xinjiang residents.

MS is a chronic, low-grade, systemic inflammatory state [11], and the relationship between MS and inflammation has long been acknowledged. Indeed, studies have demonstrated that inflammatory markers such as IL-6, hsCRP, FFA, and adiponectin play an important role in MS development and are closely related to the occurrence of MS and its components [12, 13]. IL-6 and CRP may contribute to MS risk [14], and a sharp increase in FFA can cause both insulin resistance 
(IR) in the liver, increase the expression of proinflammatory cytokines such as IL-6, and stimulate the liver to secrete CRP [15]. Decreased adiponectin levels are also associated with IR and are observed in proinflammatory states $[16,17]$.

However, these findings were primarily obtained in highincome and urban settings, whereas little information has been gathered in low-income rural settings. Specifically, data concerning inflammatory marker levels and their relationship with MS in Uyghur and Kazakh people and data concerning differences between these two local minority groups are lacking. In this study, we analyzed the relationships between inflammation and MS and the possible differences between these ethnic groups residing in far western China to examine the reasons underlying the incidence of MS in Xinjiang.

\section{Materials and Methods}

2.1. Ethics Statement. The Institutional Ethics Review Board (IERB) at the First Affiliated Hospital of the Shihezi University School of Medicine approved the study (IERB no. SHZ2010LL01). Standard university hospital guidelines, including informed consent, voluntary participation, confidentiality, and anonymity, were followed. All of the participants provided written informed consent before the study began.

2.2. Settings and Participants. This study was conducted from 2009 to 2012 among Uyghurs residing along the Bazi Xiang River region of Jiashi and Kazakhs residing in Nalati township of Yili in Xinjiang. For the basic survey, we divided subjects from the two ethic groups into MS and non-MS groups according to the 2005 IDF criteria. Using a random number table in SPSS 19.0, we then randomly selected 218 and 156 cases from the MS groups and 201 and 180 cases from the non-MS groups of the Uyghur and Kazakh populations, respectively, for laboratory testing.

2.3. Definition of MS and HOMA-IR. (1) MS was defined by central obesity according to the IDF (modified guidelines of the WHO for the Asia Pacific region) [18], a waist circumference $\geq 90 \mathrm{~cm}$ in men or $\geq 80 \mathrm{~cm}$ in women, plus any two of the following four factors: (a) an elevated triglyceride level of $>150 \mathrm{mg} / \mathrm{dL}$ (1.69 mM); (b) a reduced HDL cholesterol level of $<40 \mathrm{mg} / \mathrm{dL}(1.04 \mathrm{mM})$ in males or $<50 \mathrm{mg} / \mathrm{dL}(1.29 \mathrm{mM})$ in females; (c) elevated $\mathrm{BP}$ (SBP $\geq 130$ or $\mathrm{DBP} \geq 85 \mathrm{mmHg}$ ); and (d) an elevated fasting plasma glucose level of $\geq 100 \mathrm{mg} / \mathrm{dL}$.

(2) The homeostasis model assessment of insulin resistance (HOMA-IR) index was defined as follows: fasting insulin (in microinternational units $[\mu \mathrm{IU}]$ per $\mathrm{mL}$ ) $\times$ fasting glucose (in $\mathrm{mM}$ )/22.5 [19]. The Chinese Diabetes Society (CDS) states that IR can be estimated using this formula in epidemiological or clinical studies, and the upper quartile of the subjects was the split point for this study: 1.17 in Uyghurs and 1.23 in Kazakhs.

2.4. Exclusion Criteria. The exclusion criteria were as follows: (1) patients with serious heart and liver dysfunction; (2) patients using insulin and oral hypoglycemic, antihypertensive, lipid-lowering drugs; (3) pregnant women; (4) patients with cancer or tuberculosis or other infectious diseases.

2.5. Laboratory Tests. (1) Total cholesterol (TC), triglyceride (TG), low-density lipoprotein cholesterol (LDL-C), highdensity lipoprotein cholesterol (HDL-C), and fasting glucose levels were assessed using a biochemical autoanalyzer (Olympus AU 2700, Olympus Diagnostics, Hamburg, Germany) in a clinical laboratory.

(2) IL-6 and adiponectin levels were determined by ELISA with kits purchased from Shanghai Westang Bio-Tech Co., Ltd. (Shanghai, China). hsCRP was determined by immunonephelometry, and FFA was determined by a colorimetric assay; the kits were purchased from Randox Laboratories Ltd. (UK). Insulin levels were determined by radioimmunoassay using a kit purchased from Beijing Atomic-Tech Co., Ltd. (Beijing, China).

2.6. Statistical Analysis. All of the analyses were performed using the SPSS statistical package for Windows (version 19.0). Continuously and normally distributed variables were analyzed using $t$-tests, and the results are presented as the means \pm standard deviations $(M \pm S D)$; variables with a skewed distribution were analyzed using the Mann-Whitney $U$-test, and the results are expressed as the median (upper quartile, lower quartile) $\left[\mathrm{M}\left(\mathrm{Q}_{\mathrm{u}}, \mathrm{Q}_{\mathrm{L}}\right)\right]$. All of the rates were compared using the Chi-square test. Differences of $P<0.05$ were considered to be statistically significant.

\section{Results}

3.1. Description of the General Situation in the Uyghur and Kazakh Populations. Average age and gender were not significantly different between the MS and non-MS groups in the Uyghur and Kazakh populations or between the two ethnicities ( $P>0.05$ for each comparison). Among Uyghurs and Kazakhs, BMI, WC, SBP, DBP, TG, HDL-C, FPG, LDL-C, and TC levels were higher in the MS group than in the nonMS group $(P<0.05$ for each comparison). However, there were no differences between the two ethnicities, regardless of whether they were classified in the MS or non-MS group ( $P>0.05$ for each comparison) (Table 1$)$.

3.2. Serum IL-6, hsCRP, FFA, and Adiponectin Levels for Uyghurs and Kazakhs in the MS and Non-MS Groups. In both the Uyghur and Kazakh populations, serum IL-6, hsCRP, and FFA levels in the MS group were higher than those in the non-MS group; overall, the levels recorded in Kazakhs were higher than those measured in Uyghurs, both with and without MS ( $P<0.01$ for each comparison). Conversely, adiponectin levels displayed the opposite trends $(P<0.01$ for each comparison) (Table 2).

3.3. Detection Rates of MS and Its Components between Each Group by Quartile Assessment of Serum IL-6, hsCRP, FFA, and Adiponectin Levels in Uyghurs and Kazakhs $\left(Q_{1}\right.$ Group, Less Than the 25th Percentile; $Q_{2}$ Group, 25th to 50th Percentile; 
TABle 1: Age and gender data for the Uyghur and Kazakh subjects.

\begin{tabular}{lcccc}
\hline Index & \multicolumn{2}{c}{ Uyghur } & \multicolumn{2}{c}{ Kazakh } \\
& MS $(n=218)$ & Non-MS $(n=201)$ & MS $(n=156)$ & Non-MS $(n=180)$ \\
\hline Sex $($ male/female $)$ & $104 / 114$ & $95 / 106$ & $42 / 82$ & $88 / 92$ \\
Age $($ years $)$ & $41.49 \pm 12.42$ & $41.86 \pm 11.90$ & $27.06 \pm 4.25^{\#}$ & $40.71 \pm 10.24$ \\
BMI $\left(\mathrm{kg} / \mathrm{m}^{2}\right)$ & $24.03 \pm 1.73^{\#}$ & $22.54 \pm 2.53$ & $95.26 \pm 10.10^{\#}$ & $21.76 \pm 2.01$ \\
WC $(\mathrm{cm})$ & $92.76 \pm 7.28^{\#}$ & $82.73 \pm 9.09$ & $142.98 \pm 22.98^{\#}$ & $82.89 \pm 9.32$ \\
SBP $(\mathrm{mmHg})$ & $140.41 \pm 20.10^{\#}$ & $112.95 \pm 11.59$ & $92.91 \pm 13.96^{\#}$ & $116.60 \pm 18.24$ \\
DBP $(\mathrm{mmHg})$ & $93.07 \pm 12.56^{\#}$ & $85.24 \pm 10.23$ & $1.68 \pm 1.13^{\#}$ & $86.51 \pm 14.79$ \\
TG $(\mathrm{mmol} / \mathrm{L})$ & $1.64 \pm 0.99^{\#}$ & $0.86 \pm 0.32$ & $1.01 \pm 0.28^{\#}$ & $0.95 \pm 0.37$ \\
HDL-C (mmol/L) & $1.06 \pm 0.25^{\#}$ & $1.58 \pm 0.29$ & $5.01 \pm 1.64^{\#}$ & $1.54 \pm 0.40$ \\
FPG $(\mathrm{mmol} / \mathrm{L})$ & $4.89 \pm 1.33^{\#}$ & $4.49 \pm 0.56$ & $2.65 \pm 0.81^{\#}$ & $4.51 \pm 0.95$ \\
LDL-C (mmol/L) & $2.68 \pm 0.72^{\#}$ & $2.27 \pm 0.70$ & $4.98 \pm 1.13^{\#}$ & $2.25 \pm 0.66$ \\
TC (mmol/L) & $4.72 \pm 1.08^{\#}$ & $4.16 \pm 0.99$ & $4.20 \pm 0.95$ \\
\hline
\end{tabular}

Notes: $\mathrm{MS}=$ metabolicsyndrome, $\mathrm{WC}=$ waist circumference, $\mathrm{BMI}=$ body mass index $\mathrm{SBP}=$ systolic blood pressure, $\mathrm{DBP}=$ diastolic blood pressure, $\mathrm{TG}=$ triglyceride, TC = total cholesterol, HDL-C = high-density lipoprotein cholesterol, LDL-C = low-density lipoprotein cholesterol, and FPG = fasting plasma glucose. "Comparing the index in the same ethnicity, $P<0.05$.

TABLE 2: IL-6, hsCRP, FFA and adiponectin levels of MS and non-MS groups in the Uyghur and Kazakh populations.

\begin{tabular}{|c|c|c|c|c|c|c|c|c|}
\hline & \multicolumn{4}{|c|}{ Uyghur } & \multicolumn{4}{|c|}{ Kazakh } \\
\hline & IL-6 (ng/L) & $\begin{array}{l}\text { hsCRP } \\
(\mathrm{mg} / \mathrm{L})\end{array}$ & FFA (mg/L) & Adiponectin (pg/L) & IL-6 (ng/L) & $\begin{array}{l}\text { hsCRP } \\
(\mathrm{mg} / \mathrm{L})\end{array}$ & FFA (mg/L) & $\begin{array}{l}\text { Adiponectin } \\
\text { (pg/L) }\end{array}$ \\
\hline MS & $\begin{array}{c}30.86 \\
(21.22,43.89)^{*}\end{array}$ & $\begin{array}{c}1.26 \\
(0.79,1.52)^{*}\end{array}$ & $\begin{array}{c}0.57 \\
(0.38,0.80)^{*}\end{array}$ & $\begin{array}{c}4405.54 \\
(2524.4,15964.34)^{*}\end{array}$ & $\begin{array}{c}88.12 \\
(44.20,197.02)\end{array}$ & $\begin{array}{c}3.20 \\
(1.70,5.50)\end{array}$ & $\begin{array}{c}0.61 \\
(0.48,0.77)\end{array}$ & $\begin{array}{c}446.17 \\
(103.03,1796.71)\end{array}$ \\
\hline Non-MS & $\begin{array}{c}23.32 \\
(11.09,31.81)^{*}\end{array}$ & $\begin{array}{c}1.16 \\
(0.79,1.35)^{*}\end{array}$ & $\begin{array}{c}0.45 \\
(0.33,0.65)^{*}\end{array}$ & $\begin{array}{c}5724.58 \\
(1824.22,16388.89)^{*}\end{array}$ & $\begin{array}{c}62.58 \\
(14.20,159.90)\end{array}$ & $\begin{array}{c}1.50 \\
(0.60,4.50)\end{array}$ & $\begin{array}{c}0.49 \\
(0.34,0.59)\end{array}$ & $\begin{array}{c}841.71 \\
(298.80,2716.31)\end{array}$ \\
\hline$Z$ & -5.852 & -2.550 & -4.398 & -3.730 & -3.456 & -4.911 & -5.518 & -3.783 \\
\hline$P$ & $<0.001$ & 0.011 & $<0.001$ & $<0.001$ & $<0.001$ & $<0.001$ & $<0.001$ & $<0.001$ \\
\hline
\end{tabular}

Notes: MS = metabolic syndrome, IL- $6=$ interleukin- $6, \mathrm{CRP}=\mathrm{C}$-reactive protein, and FFA $=$ free fatty acids.

${ }^{*}$ Comparing the same index between the two ethnicities, $P<0.05$.

$Q_{3}$ Group, 50th to 75th Percentile; $Q_{4}$ Group, Greater Than the 75th Percentile). From the $\mathrm{Q}_{1}$ group to the $\mathrm{Q}_{4}$ group, the rates of detection for MS and its components in Uyghurs and Kazakhs tended to increase as the levels of IL-6, hsCRP, and FFA increased. Comparing the $\mathrm{Q}_{4}$ and $\mathrm{Q}_{1}$ groups, all $\mathrm{OR}$ values were $>1$, indicating that the $\mathrm{Q}_{4}$ group's risk was higher than that of the $\mathrm{Q}_{1}$ group. However, the adiponectin levels exhibited opposite results (Tables 3-6).

3.4. Relationship of Serum IL-6, hsCRP, FFA, and Adiponectin Levels with the Number of Clustered MS Components. As the MS component clustering increased, the serum IL-6, hsCRP, and FFA levels gradually increased in both populations $(P<$ 0.01 for each comparison); however, this trend was more obvious for Kazakh individuals, as shown in the top curve. In contrast, adiponectin levels showed the opposite trend (Figures 1-4).

\section{Discussion}

MS is a major public health problem because of its rapidly increasing prevalence and its association with type 2 diabetes and cardiovascular disease (CVD) [20]. In fact, CVD risk in patients with MS is twice that of the normal population [3].
In the United States, Europe, and India, at least 25\% of adults suffer from MS. However, the reasons underling the high incidence of MS have not been confirmed. Related studies have demonstrated that MS is associated with a proinflammatory state, which is hypothesized to be related to CVD [20-23], and some inflammatory markers, such as IL-6, hsCRP, FFA, and adiponectin, are closely related to MS $[21,24,25]$.

The current study analyzed the relationship between MS and inflammation in adults of rural Kazakh and Uyghur populations in northwest China. We determined that, for both populations, IL-6, hsCRP, and FFA levels were higher in the MS group than in the non-MS group and that adiponectin is an adipose tissue factor that could improve IR. This trend is similar to those reported in domestic and foreign research, though the levels in our study are higher [26-28]. Nishida et al. determined that "high" IL-6 or hsCRP levels or "low" adiponectin levels are associated with an increased risk for MS. Additionally, IL-6 and adiponectin have been shown to be important risk factors for early arterial alterations in men [29]. MS incidence was found to increase with increased CRP and IL-6 levels [30], and hsCRP levels were markedly increased in older male patients with MS [31]. Moreover, hsCRP can facilitate the prediction of new-onset CVD [32]. 
TABLE 3: Detection rates of MS and components in each IL-6 level quartile.

\begin{tabular}{lcccccccccccc}
\hline \multirow{2}{*}{ MS and components } & \multicolumn{1}{c}{ Uyghur } & \multicolumn{4}{c}{ Kazakh } \\
& $\mathrm{Q}_{1}$ & $\mathrm{Q}_{2}$ & $\mathrm{Q}_{3}$ & $\mathrm{Q}_{4}$ & $P$ & $\mathrm{OR}\left(\mathrm{Q}_{4} / \mathrm{Q}_{1}\right)(\mathrm{OR} 95 \% \mathrm{CI})$ & $\mathrm{Q}_{1}$ & $\mathrm{Q}_{2}$ & $\mathrm{Q}_{3}$ & $\mathrm{Q}_{4}$ & $P$ & $\mathrm{OR}\left(\mathrm{Q}_{4} / \mathrm{Q}_{1}\right)(\mathrm{OR} 95 \% \mathrm{CI})$ \\
\hline MS & 7.6 & 13.4 & 12.9 & 18.4 & 0.000 & $6.27(3.444,11.429)$ & 12.1 & 16.2 & 17.5 & 16.2 & 0.015 & $2.14(1.128,4.049)$ \\
Hypertension & 4.5 & 9.8 & 8.6 & 14.6 & 0.000 & $6.28(3.341,11.784)$ & 10.8 & 14.6 & 15.9 & 14.9 & 0.018 & $2.10(1.113,3.946)$ \\
Low HDL-C & 19.3 & 19.1 & 18.1 & 22.9 & 0.000 & $10.58(3.579,31.261)$ & 7.6 & 11.1 & 12.4 & 11.7 & 0.020 & $2.14(1.117,4.113)$ \\
High TG & 3.6 & 7.2 & 6.4 & 10.3 & 0.000 & $4.16(2.128,8.139)$ & 2.9 & 3.5 & 7.6 & 13.0 & 0.000 & $8.87(3.892,20.193)$ \\
High FPG & 1.4 & 1.7 & 1.0 & 2.9 & 0.196 & $2.13(1.768,5.904)$ & 4.4 & 7.0 & 8.9 & 9.8 & 0.001 & $3.16(1.517,6.570)$ \\
\hline
\end{tabular}

Notes: $\mathrm{MS}=$ metabolicsyndrome, $\mathrm{TG}=$ triglyceride, $\mathrm{HDL}-\mathrm{C}=$ high-density lipoprotein cholesterol, $\mathrm{FPG}=$ fasting plasma glucose, $\mathrm{OR}=\mathrm{odds}$ ratio, and $\mathrm{CI}=$ confidence interval.

TABLE 4: Detection rates of MS and components in each hsCRP level quartile.

\begin{tabular}{lcccccccccccc}
\hline \multirow{2}{*}{ MS and components } & \multicolumn{1}{c}{ Uyghur } & \multicolumn{4}{c}{ Kazakh } \\
& $\mathrm{Q}_{1}$ & $\mathrm{Q}_{2}$ & $\mathrm{Q}_{3}$ & $\mathrm{Q}_{4}$ & $P$ & $\mathrm{OR}\left(\mathrm{Q}_{4} / \mathrm{Q}_{1}\right)(\mathrm{OR} 95 \% \mathrm{CI})$ & $\mathrm{Q}_{1}$ & $\mathrm{Q}_{2}$ & $\mathrm{Q}_{3}$ & $\mathrm{Q}_{4}$ & $P$ & $\mathrm{OR}\left(\mathrm{Q}_{4} / \mathrm{Q}_{1}\right)(\mathrm{OR} 95 \% \mathrm{CI})$ \\
\hline MS & 13.1 & 10.7 & 10.5 & 17.7 & 0.015 & $2.17(1.230,3.829)$ & 7.0 & 18.7 & 19.0 & 17.1 & 0.000 & $4.81(2.428,9.548)$ \\
Hypertension & 7.4 & 9.5 & 7.9 & 12.6 & 0.008 & $2.43(1.379,4.292)$ & 5.7 & 17.1 & 17.5 & 15.9 & 0.000 & $5.09(2.532,10.242)$ \\
Low HDL-C & 17.7 & 18.4 & 19.3 & 24.1 & 0.030 & $3.16(1.390,7.184)$ & 5.1 & 12.7 & 12.1 & 13.0 & 0.001 & $3.75(1.847,7.594)$ \\
High TG & 6.0 & 6.2 & 6.0 & 9.3 & 0.047 & $1.89(1.039,3.441)$ & 1.0 & 3.5 & 8.6 & 14.0 & 0.000 & $28.52(8.280,98.222)$ \\
High FPG & 3.1 & 1.0 & 1.4 & 1.4 & 0.101 & $1.43(1.057,1.675)$ & 2.2 & 8.3 & 8.9 & 9.8 & 0.001 & $6.97(2.844,17.079)$ \\
\hline
\end{tabular}

Notes: $\mathrm{MS}=$ metabolic syndrome, $\mathrm{TG}=$ triglyceride, $\mathrm{HDL}-\mathrm{C}=$ high-density lipoprotein cholesterol, $\mathrm{FPG}=$ fasting plasma glucose, $\mathrm{OR}=\mathrm{odds}$ ratio, and $\mathrm{CI}=$ confidence interval.

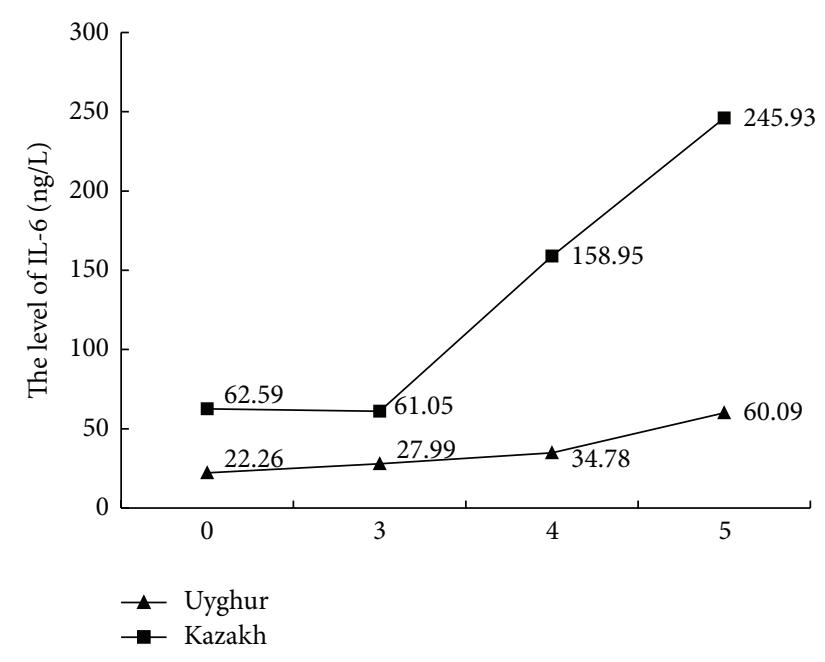

FIGURE 1: Comparing IL-6 with MS components.

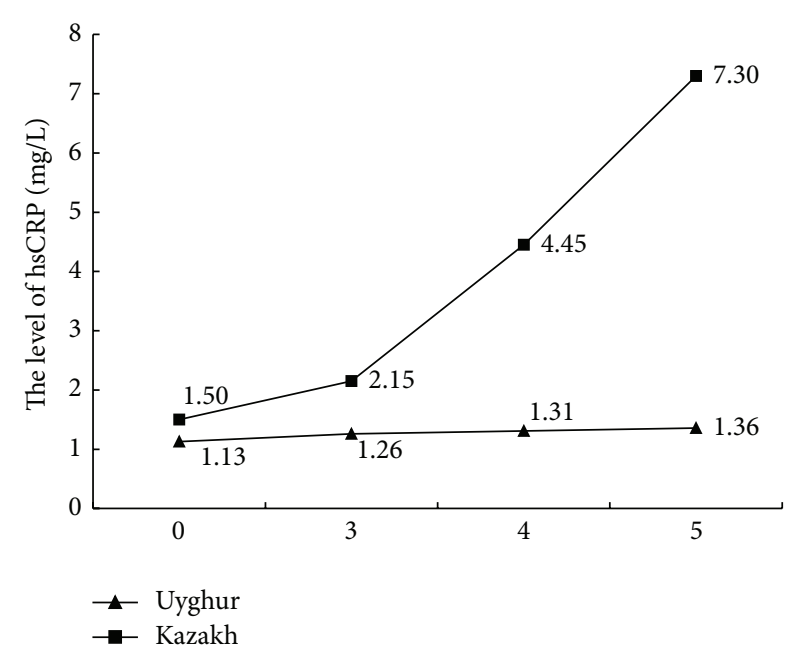

FIGURE 2: Comparing hsCRP with MS components.
IL-6, hsCRP, and FFA appear to promote MS development, whereas adiponectin negatively regulates MS by suppressing IR, ultimately preventing MS.

Nishida et al. reported that individuals with an increased number of MS components have higher CRP levels [29]. In another study, when the number of components $\geq 3$, FFA levels were notably increased, with a decrease in adiponectin levels [28]. The results of the present study demonstrated that IL-6, hsCRP, and FFA levels also increased among Uyghurs and Kazakhs as the clustering of MS components increased, though adiponectin levels decreased. We also analyzed the subjects according to quartiles of IL-6, hsCRP, FFA, and adiponectin levels and compared the detection rates of MS and its components from the $\mathrm{Q}_{1}$ group to the $\mathrm{Q}_{4}$ group. The results demonstrated increasing trends for the levels of IL-6, hsCRP, and FFA. Moreover, the OR values were $>1$ for the $\mathrm{Q}_{4}$ and $\mathrm{Q}_{1}$ groups, predicting that the incidence risk of $\mathrm{MS}$ and its components is higher in the $\mathrm{Q}_{4}$ group. However, the opposite trends were observed with increased adiponectin levels.

Uyghurs and Kazakhs are the two main ethnic groups in Xinjiang, and their unique geographical environment and living habits are very different from those of the rest of the country. For instance, their economy is primitive, their environment is harsh, their education and medical knowledge are deficient, and their self-awareness of prevention and 
TABLE 5: Detection rates of MS and components in each FFA level quartile.

\begin{tabular}{lcccccccccccc}
\hline \multirow{2}{*}{ MS and components } & \multicolumn{1}{c}{ Uyghur } & \multicolumn{1}{c}{ Kazakh } \\
& $\mathrm{Q}_{1}$ & $\mathrm{Q}_{2}$ & $\mathrm{Q}_{3}$ & $\mathrm{Q}_{4}$ & $P$ & $\mathrm{OR}\left(\mathrm{Q}_{4} / \mathrm{Q}_{1}\right)(\mathrm{OR} 95 \% \mathrm{CI})$ & $\mathrm{Q}_{1}$ & $\mathrm{Q}_{2}$ & $\mathrm{Q}_{3}$ & $\mathrm{Q}_{4}$ & $P$ & $\mathrm{OR}\left(\mathrm{Q}_{4} / \mathrm{Q}_{1}\right)(\mathrm{OR} 95 \% \mathrm{CI})$ \\
\hline MS & 10.7 & 10.7 & 14.1 & 16.5 & 0.001 & $2.26(1.294,3.946)$ & 7.4 & 14.0 & 8.9 & 16.1 & 0.003 & $3.44(1.800,6.582)$ \\
Hypertension & 6.9 & 7.4 & 11.2 & 11.9 & 0.001 & $2.18(1.226,3.868)$ & 11.3 & 14.6 & 11.0 & 13.7 & 0.926 & $1.15(1.620,2.433)$ \\
Low HDL-C & 18.4 & 18.1 & 19.8 & 23.2 & 0.005 & $3.02(1.364,6.702)$ & 6.3 & 9.6 & 6.9 & 11.0 & 0.095 & $1.98(1.023,3.825)$ \\
High TG & 6.0 & 5.7 & 6.2 & 9.5 & 0.040 & $1.82(1.698,3.300)$ & 3.0 & 6.3 & 3.3 & 6.0 & 0.305 & $2.00(1.370,4.597)$ \\
High FPG & 0.7 & 1.7 & 1.9 & 2.6 & 0.041 & $1.34(1.130,2.306)$ & 4.3 & 6.2 & 5.8 & 6.2 & 0.939 & $1.04(1.437,2.456)$ \\
\hline
\end{tabular}

Notes: $\mathrm{MS}=$ metabolic syndrome, $\mathrm{TG}=$ triglyceride, $\mathrm{HDL}-\mathrm{C}=$ high-density lipoprotein cholesterol, $\mathrm{FPG}=$ fasting plasma glucose, $\mathrm{OR}=\mathrm{odds}$ ratio, and $\mathrm{CI}=$ confidence interval.

TABLE 6: Detection rates of MS and components in each adiponectin level quartile.

\begin{tabular}{lcccccccccccc}
\hline \multirow{2}{*}{ MS and components } & \multicolumn{1}{c}{ Uyghur } & \multicolumn{1}{c}{ Kazakh } \\
& $\mathrm{Q}_{1}$ & $\mathrm{Q}_{2}$ & $\mathrm{Q}_{3}$ & $\mathrm{Q}_{4}$ & $P$ & $\mathrm{OR}\left(\mathrm{Q}_{4} / \mathrm{Q}_{1}\right)(\mathrm{OR} 95 \% \mathrm{CI})$ & $\mathrm{Q}_{1}$ & $\mathrm{Q}_{2}$ & $\mathrm{Q}_{3}$ & $\mathrm{Q}_{4}$ & $P$ & $\mathrm{OR}\left(\mathrm{Q}_{4} / \mathrm{Q}_{1}\right)(\mathrm{OR} 95 \% \mathrm{CI})$ \\
\hline MS & 17.9 & 12.4 & 10.7 & 11.0 & 0.000 & $0.31(0.176,0.553)$ & 13.4 & 14.6 & 11.0 & 7.4 & 0.000 & $0.37(0.195,0.693)$ \\
Hypertension & 9.5 & 10.0 & 9.1 & 8.8 & 0.323 & $0.88(0.504,1.550)$ & 13.1 & 14.0 & 13.1 & 10.4 & 0.144 & $0.65(0.353,1.194)$ \\
Low HDL-C & 24.6 & 18.6 & 16.7 & 19.6 & 0.000 & $0.07(0.016,0.302)$ & 8.7 & 9.6 & 7.8 & 7.8 & 0.109 & $0.86(0.453,1.651)$ \\
High TG & 11.2 & 4.8 & 6.2 & 5.3 & 0.001 & $0.33(0.178,0.600)$ & 5.7 & 6.6 & 3.6 & 2.7 & 0.013 & $0.42(0.176,0.983)$ \\
High FPG & 3.8 & 1.7 & 0.7 & 0.7 & 0.000 & $0.16(0.046,0.580)$ & 5.4 & 8.6 & 5.8 & 2.7 & 0.156 & $0.50(0.187,1.334)$ \\
\hline
\end{tabular}

Notes: $\mathrm{MS}=$ metabolic syndrome, $\mathrm{TG}=$ triglyceride, $\mathrm{HDL}-\mathrm{C}=$ high-density lipoprotein cholesterol, $\mathrm{FPG}=$ fasting plasma glucose, $\mathrm{OR}=\mathrm{odds}$ ratio, and $\mathrm{CI}=$ confidence interval.

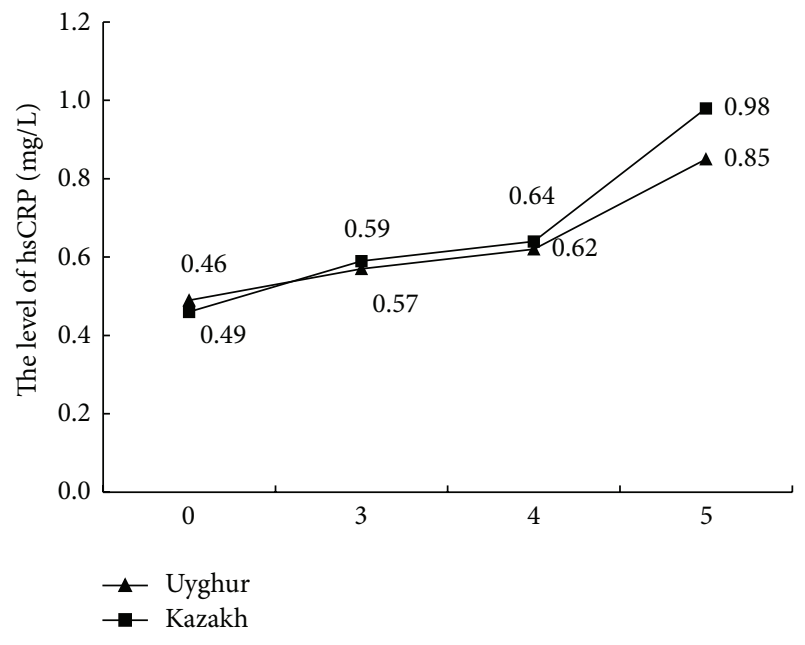

FIGURE 3: Comparing FFA with MS components.

treatment is poor. Additionally, the staple of their diet is Nang, which contains a large amount of salt, and they do not eat many fruits or vegetables. Indeed, Kazakhs consume Nang three times a day and are accustomed to drinking tea with plenty of salt and milk. They also frequently consume cured meat, which may lead to higher prevalence of MS and its components in Kazakhs compared to Uyghurs. The reported prevalence of MS in Kazakhs is 26.6\% [8], whereas that in Uyghurs is $21.2 \%$ [9]. In our study, IL-6, hsCRP, and FFA levels were higher in Kazakhs than in Uyghurs, and the positive association with MS components was more obvious in the former; the results for adiponectin displayed the opposite trend. These observations provide further evidence

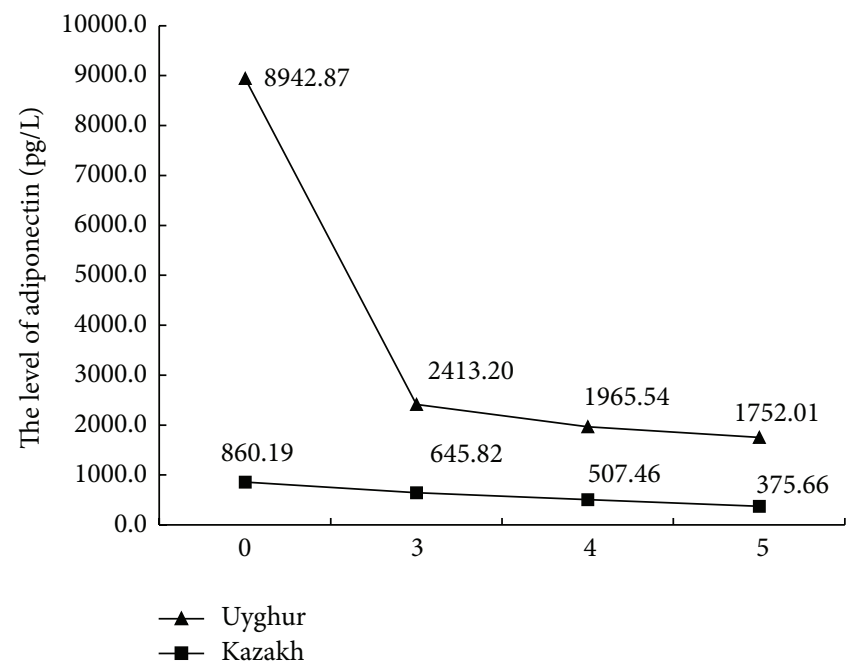

FIGURE 4: Comparing adiponectin with MS components.

that IL-6, hsCRP, and FFA levels are positively correlated with the occurrence of MS and that adiponectin is negatively correlated with MS.

We could not establish causal relationships in our study due to its cross-sectional design, and we did not collect data on the socioeconomic or environmental variables that could have an impact on MS. We also recruited subjects during a local investigation in northwest China and not from hospitals or other medical institutions. Subjects from hospitals or other medical institutions could be more representative, and the use of such a sample could have allowed us to explore the relationship between $\mathrm{MS}$ and inflammation over a range 
of demographic groups. Nonetheless, these findings provide important demographic insight into the growing problem of MS in rural Kazakh and Uyghur populations.

\section{Conclusion}

In conclusion, this study explored the relationship between MS and inflammation among Uyghur and Kazakh people. Despite the higher prevalence of MS in these groups compared with the rest of China, to date, few studies have investigated the underlying reasons for this higher prevalence. We observed that the abnormal expression of inflammatory cytokines might contribute to the high prevalence of MS, which could be associated with the characteristics of the different ethnicities and areas (e.g., differences in living environments, habits, and customs). To prevent MS, these groups could improve their lifestyle behaviors through education or medication to control IL-6, hsCRP, FFA, and adiponectin levels. Therefore, our observations and recommendations should be used to establish appropriate public health policies to benefit low-income populations.

\section{Abbreviations}

$\begin{array}{ll}\text { BMI: } & \text { Body mass index } \\ \text { BP: } & \text { Blood pressure } \\ \text { CI: } & \text { Confidence interval } \\ \text { CRP: } & \text { C-reactive protein } \\ \text { FBG: } & \text { Fasting blood glucose } \\ \text { HDL-C: } & \text { High-density lipoprotein cholesterol } \\ \text { HOMA-IR: } & \text { Homeostasis model assessment of insulin } \\ & \text { resistance } \\ \text { IL-6: } & \text { Interleukin-6 } \\ \text { IR: } & \text { Insulin resistance } \\ \text { LDL-C: } & \text { Low-density lipoprotein cholesterol } \\ \text { MS: } & \text { Metabolic syndrome } \\ \text { OR: } & \text { Odds ratio } \\ \text { TC: } & \text { Total cholesterol } \\ \text { FFA: } & \text { Free fatty acids. }\end{array}$

\section{Conflict of Interests}

The authors declare that there is no conflict of interests regarding the publication of this paper.

\section{Authors' Contribution}

Yi-Zhong Yan and Ru-Lin Ma contributed equally to this work.

\section{Acknowledgments}

The authors sincerely thank those who participated in the study. They are grateful to the Jiashi and Xinyuan County Governments, the County Health Bureau, and their employees for field assistance. This research was supported by the National Key Technology R\&D Program of China (Grant no.
2009BAI82B04) and the Key Laboratory of Xinjiang Endemic and Ethnic Diseases.

\section{References}

[1] T. Chimonas, V. G. Athyros, E. Ganotakis et al., "Cardiovascular risk factors and estimated 10-year risk of fatal cardiovascular events using various equations in Greeks with metabolic syndrome," Angiology, vol. 61, no. 1, pp. 49-57, 2010.

[2] D. Kobayashi, O. Takahashi, G. A. Deshpande, T. Shimbo, and T. Fukui, "Relation between metabolic syndrome and sleep duration in Japan: a large scale cross-sectional study," Internal Medicine, vol. 50, no. 2, pp. 103-107, 2011.

[3] E. Kassi, P. Pervanidou, G. Kaltsas, and G. Chrousos, "Metabolic syndrome: definitions and controversies," BMC Medicine, vol. 9, article 48, 2011.

[4] G. Schillaci, M. Pirro, G. Vaudo et al., "Prognostic value of the metabolic syndrome in essential hypertension," Journal of the American College of Cardiology, vol. 43, no. 10, pp. 1817-1822, 2004.

[5] J. He, S. Guo, J. Liu et al., "Ethnic differences in prevalence of general obesity and abdominal obesity among low-income rural Kazakh and Uyghur adults in far western China and implications in preventive public health," PLoS ONE, vol. 9, no. 9, Article ID e106723, 2014.

[6] L. Cong, J. Q. Zhan, L. Yang et al., "Overweight and obesity among low-income muslim uyghur women in far western china: correlations of body mass index with blood lipids and implications in preventive public health," PLoS ONE, vol. 9, no. 2, Article ID e90262, 2014.

[7] W. J. Zhang, F. Li, Y. H. Wang et al., "The case for semimandatory HPV vaccination in China," Nature Biotechnology, vol. 31, no. 7, pp. 590-591, 2013.

[8] C. H. Li, S. X. Guo, R. L. Ma et al., "The epidemic situation of metabolic syndrome among the Uygur in Kazakhs of Xinjiang in 2010," Chinese Journal of Preventive Medicine, vol. 46, no. 5, pp. 419-423, 2012.

[9] H. Guo, S. Guo, J. Y. Zhang et al., "Study on the prevalence of metabolic syndrome among the Kazakh population in Xinjiang," Chinese Journal of Epidemiology, vol. 31, pp. 747-750, 2010.

[10] D. Gu, K. Reynolds, W. Yang et al., "The prevalence of metabolic syndrome in the general adult population aged 35-74 years in China," Chinese Journal of Diabetes, vol. 13, no. 3, pp. 181-186, 2005.

[11] D. T. Nash, "Relationship of C-reactive protein, metabolic syndrome and diabetes mellitus: potential role of statins," Journal of the National Medical Association, vol. 97, no. 12, pp. 1600-1607, 2005.

[12] J. C. Felger and F. E. Lotrich, "Inflammatory cytokines in depression: neurobiological mechanisms and therapeutic implications," Neuroscience, vol. 246, pp. 199-229, 2013.

[13] R. Azar, R. P. Nolan, and D. E. Stewart, "Listening to the heart-brain talk: persistent depressive symptoms are associated with hsCRP in apparently healthy individuals at high risk for coronary artery disease," European Journal of Preventive Cardiology, vol. 19, no. 4, pp. 857-863, 2012.

[14] A. T. Kraja, M. A. Province, D. Arnett et al., "Do inflammation and procoagulation biomarkers contribute to the metabolic syndrome cluster?" Nutrition \& Metabolism, vol. 4, article 28, 2007. 
[15] A. Oberbach, N. Schlichting, M. Blüher et al., "Palmitate induced IL-6 and MCP-1 expression in human bladder smooth muscle cells provides a link between diabetes and urinary tract infections," PLoS ONE, vol. 5, no. 5, Article ID e10882, 2010.

[16] M. Fasshauer, R. Paschke, and M. Stumvoll, "Adiponectin, obesity, and cardiovascular disease," Biochimie, vol. 86, no. 11, pp. 779-784, 2004.

[17] B. B. Duncan, M. I. Schmidt, J. S. Pankow et al., "Adiponectin and the development of type 2 diabetes: the atherosclerosis risk in communities study," Diabetes, vol. 53, no. 9, pp. 2473-2478, 2004.

[18] D. R. Matthews, J. P. Hosker, A. S. Rudenski, B. A. Naylor, D. F. Treacher, and R. C. Turner, "Homeostasis model assessment: insulin resistance and $\beta$-cell function from fasting plasma glucose and insulin concentrations in man," Diabetologia, vol. 28, no. 7, pp. 412-419, 1985.

[19] K. G. M. M. Alberti, P. Zimmet, J. Shaw, and IDF Epidemiology Task Force Consensus Group, "The metabolic syndrome-a new worldwide definition," The Lancet, vol. 366, no. 9491, pp. 1059-1062, 2005.

[20] R. H. Eckel, S. M. Grundy, and P. Z. Zimmet, "The metabolic syndrome," The Lancet, vol. 365, no. 9468, pp. 1415-1428, 2005.

[21] I. J. Lodhi, L. Yin, A. P. L. Jensen-Urstad et al., "Inhibiting adipose tissue lipogenesis reprograms thermogenesis and PPAR $\gamma$ activation to decrease diet-induced obesity," Cell Metabolism, vol. 16, no. 2, pp. 189-201, 2012.

[22] C. de Luca and J. M. Olefsky, "Inflammation and insulin resistance," FEBS Letters, vol. 582, no. 1, pp. 97-105, 2008.

[23] S. A. Ritchie and J. M. C. Connell, "The link between abdominal obesity, metabolic syndrome and cardiovascular disease," Nutrition, Metabolism and Cardiovascular Diseases, vol. 17, no. 4, pp. 319-326, 2007.

[24] L. W. Xing, L. Zhang, K. Youker et al., "Free fatty acids inhibit insulin signaling-stimulated endothelial nitric oxide synthase activation through upregulating PTEN or inhibiting Akt kinase," Diabetes, vol. 55, no. 8, pp. 2301-2310, 2006.

[25] F. Ziemke and C. S. Mantzoros, "Adiponectin in insulin resistance: lessons from translational research," American Journal of Clinical Nutrition, vol. 91, no. 1, pp. 2585-2615, 2010.

[26] G. K. Shetty, P. A. Economides, E. S. Horton, C. S. Mantzoros, and A. Veves, "Circulating adiponectin and resistin levels in relation to metabolic factors, inflammatory markers, and vascular reactivity in diabetic patients and subjects at risk for diabetes," Diabetes Care, vol. 27, no. 10, pp. 2450-2457, 2004.

[27] X. J. Zhang, M. Li, S. Gao, Y. H. Wang, and S. J. Liu, "Relationship between metabolic syndrome and adipnkines on diabetes among high-risk populations," Chinese Journal of Epidemiology, vol. 33, pp. 418-422, 2012.

[28] J. Q. Li, Y. X. Dai, and Y. M. Liu, "Comparison of serum adiponectin, free fatty acid composition, and other lipid metabolic parameters among patients with different component numbers of metabolic syndrome," Chinese Journal of Diabetes, vol. 26, pp. 323-326, 2010.

[29] M. Nishida, T. Moriyama, K. Ishii et al., "Effects of IL-6, adiponectin, CRP and metabolic syndrome on subclinical atherosclerosis," Clinica Chimica Acta, vol. 384, pp. 99-104, 2007.

[30] Y. Q. Bao, W. P. Jia, L. Chen et al., "Relationship between Creactive protein level and metabolic syndro me and components," Zhong Hua Yi Xue Za Zhi, vol. 86, pp. 2105-2109, 2006.
[31] L. X. Chen, S. D. Zhang, L. L. Zhu, and M. Sun, "Association of metabolic syndrome with serum interleukin-10 and high sensitive C reactive protein(hs-CRP) in old men," Zhong Nan Da Xue Xue Bao Yi Xue Ban, vol. 33, no. 10, pp. 970-974, 2008.

[32] M. van der Velde, A. K. Bello, A. H. Brantsma et al., "Do albuminuria and hs-CRP add to the International Diabetes Federation definition of the metabolic syndrome in predicting outcome?" Nephrology Dialysis Transplantation, vol. 27, no. 6, pp. 2275-2283, 2012. 


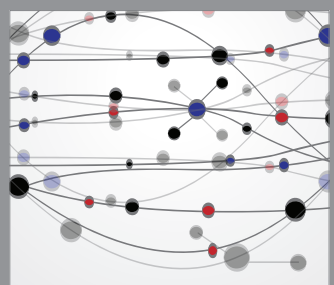

The Scientific World Journal
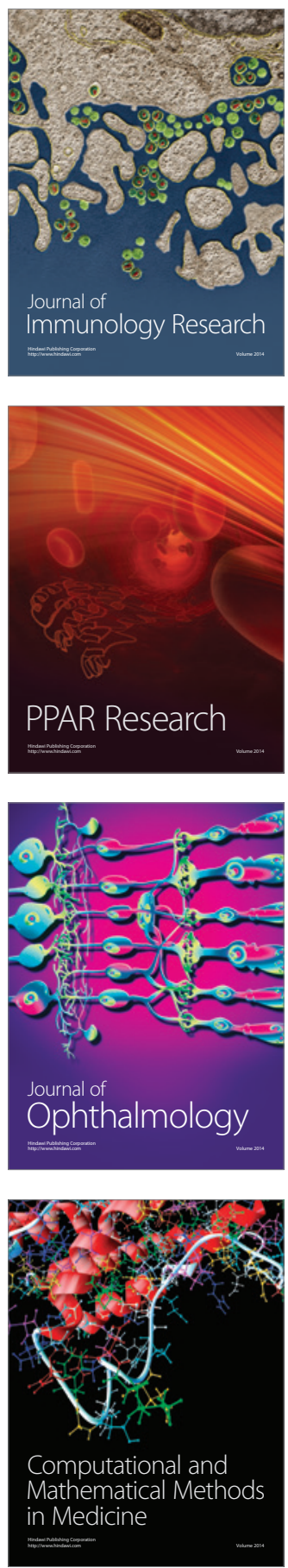

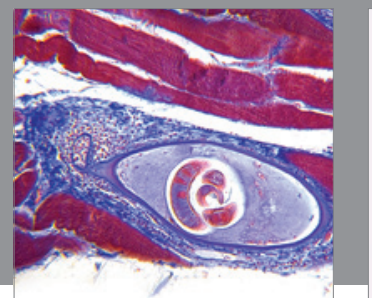

Gastroenterology

Research and Practice
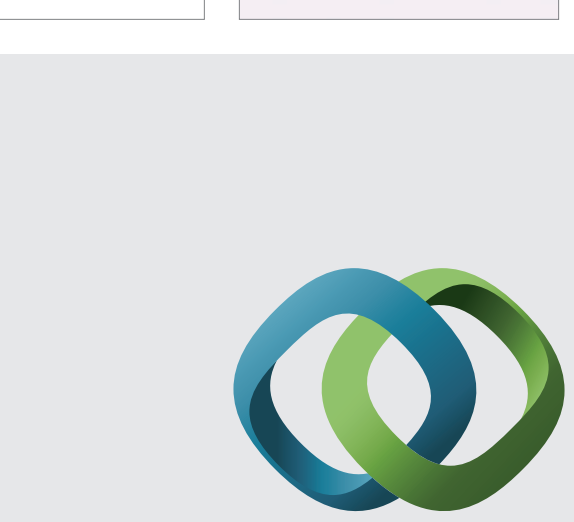

\section{Hindawi}

Submit your manuscripts at

http://www.hindawi.com
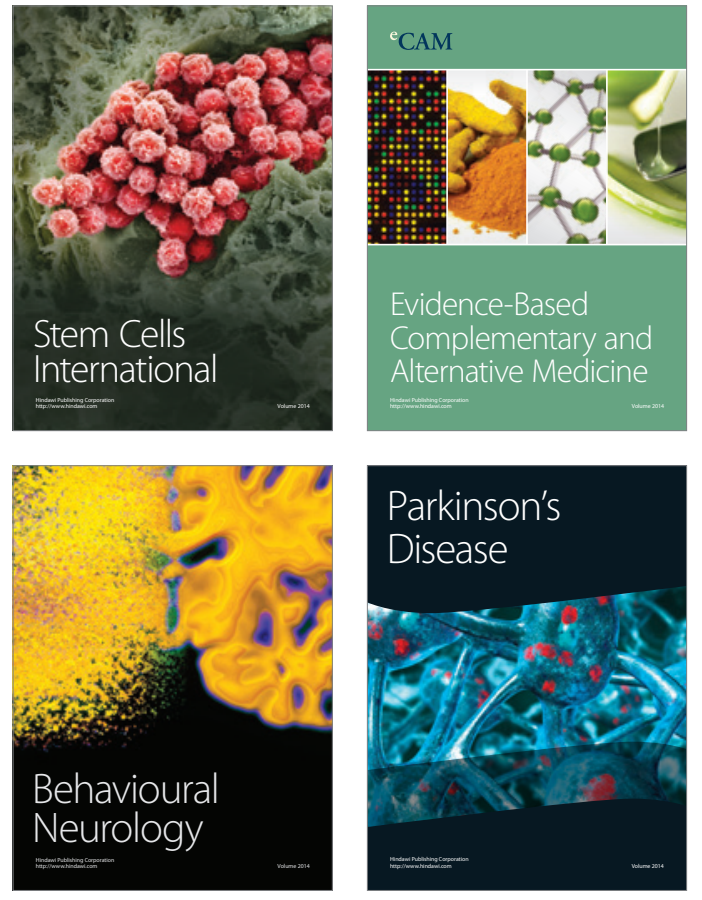
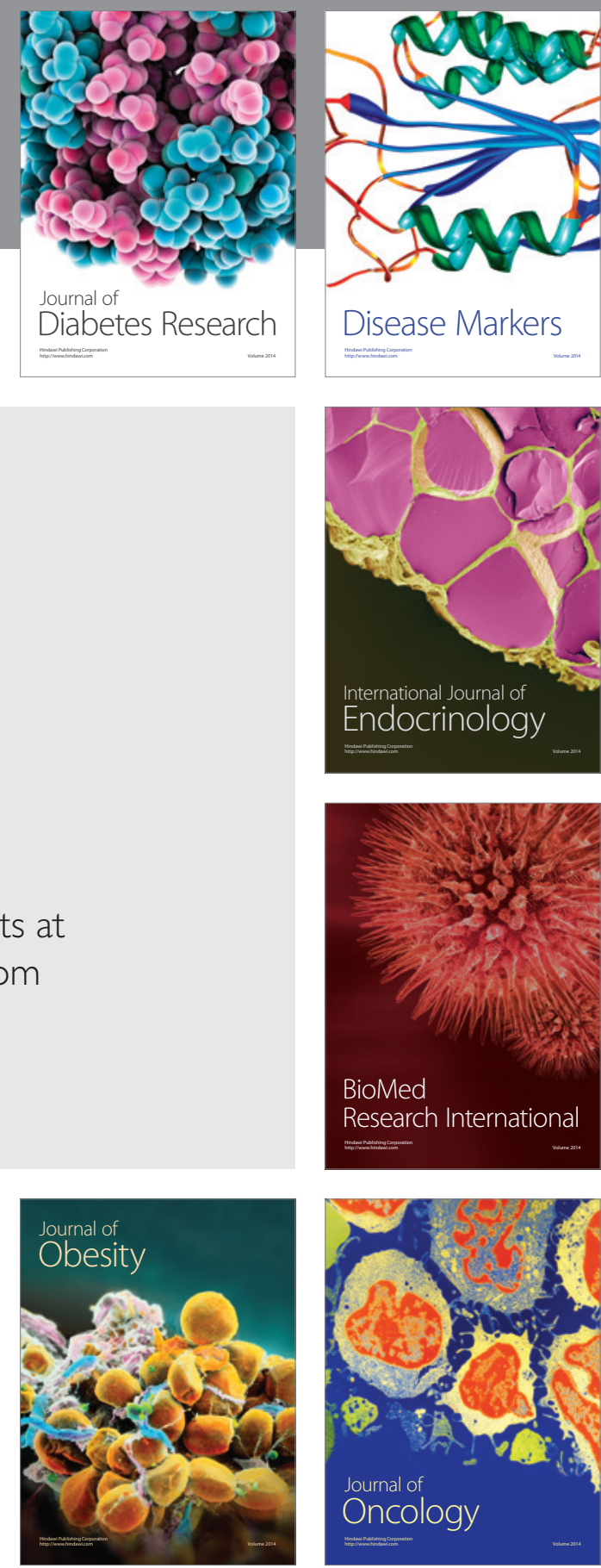

Disease Markers
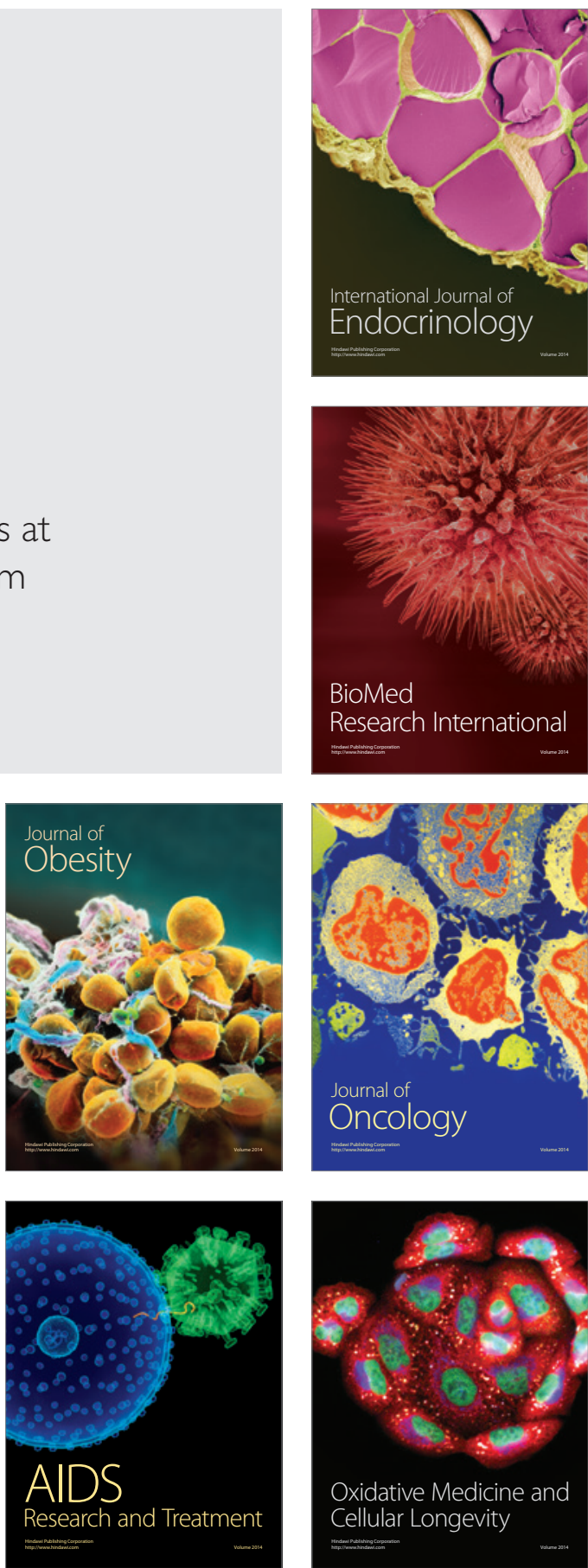